\title{
Spontaneous clearance of genital and extragenital Neisseria gonorrhoeae: data from GToG
}

\author{
Sarah Mensforth ำ , Oluseyi Cyril Ayinde 주, Jonathan Ross
}

\begin{abstract}
- Additional material is published online only. To view please visit the journal online (http://dx.doi.org/10.1136/ sextrans-2020-054500)
\end{abstract}

Department of Sexual Health and HIV, University Hospitals Birmingham NHS Foundation Trust, Birmingham, UK

\section{Correspondence to}

Dr Sarah Mensforth, Department of Sexual Health and HIV, University Hospitals Birmingham NHS Foundation Trust, Birmingham B15 2GW, UK; sarahmensforth@nhs.net

Received 16 March 2020 Revised 11 June 2020 Accepted 16 June 2020 Published Online First 30 July 2020
Check for updates

(C) Author(s) (or their employer(s)) 2020. No commercial re-use. See rights and permissions. Published by BMJ.

To cite: Mensforth $S_{\text {, }}$

Ayinde OC, Ross J.

Sex Transm Infect

2020;96:556-561

\begin{abstract}
Objectives Neisseria gonorrhoeae (NG) infection can resolve without antibiotic treatment, however the literature describing the frequency of clearance at individual sites, how rapidly it occurs and potential predictive factors is limited. In this analysis of a subpopulation identified from a large multicentre UK cohort, we describe the overall rate of spontaneous clearance of infection and explore factors associated with this.
\end{abstract}

Methods Data from the Gentamicin compared with Ceftriaxone for the Treatment of Gonorrhoea randomised controlled trial consisting of 720 patients with NG were analysed. A subgroup of individuals had both a pretrial test sample and a trial enrolment sample taken. Those who had cleared NG between initial presentation and subsequent entry into the trial without antibiotic treatment were deemed to have spontaneously cleared. Sociodemographic characteristics, sexual history and sites of infection for those who spontaneously cleared infection were compared with that of those who did not. We also estimated the time interval to clearance.

Results Overall, the proportion who had spontaneous clearance was $20.5 \%$ (83/405). Clearance of infection occurred over a median of 10 days (IQR 7-15 days). The cohort who spontaneously cleared were similar to those who did not in terms of age, gender, sexual orientation, HIV status and previous NG infection. Chlamydia coinfection was more frequent in the 'no spontaneous clearance group' $(11.1 \%(9 / 83)$ of $22.0 \%(69 / 322))(p=0.029)$. Dysuria was reported more often in the 'no spontaneous clearance group' $(4.8 \%(4 / 83)$ of $13.0 \%(42 / 322))(p=0.035)$.

Conclusion We present data from a large cohort of NG-infected individuals, of whom a significant proportion had spontaneous clearance of infection. This is consistent with previous smaller studies. If this is indicative of cure, point-of-care testing prior to treatment has the potential to reduce unnecessary exposure to antimicrobials. Further work to assess the importance of bacterial load, genotype and host immune response on spontaneous clearance of infection is required.

Trial registration number ISRCTN51783227

\section{INTRODUCTION}

In the last few decades there has been increasing concern regarding rises in the incidence of Neisseria gonorrhoeae (NG) and resistance to antibiotic treatment. ${ }^{1} \mathrm{NG}$ infection may be asymptomatic or the symptoms unrecognised, both resulting in delayed presentation to healthcare services. In the interval between infection and treatment, complications (eg, pelvic inflammatory disease or epididymo-orchitis) may arise, and onward transmission to a new sexual partner may occur.

Some STIs, including Chlamydia trachomatis (CT), can spontaneously clear without antibiotic treatment; however, the literature describing this is very limited for NG. The frequency of clearance at either extragenital or genital sites, how rapidly it occurs and potential mediating factors, such as previous infection or antibody production, have not been fully explored. $^{2}$ The pharynx is the most common site from which spontaneous clearance of NG has previously been reported, ${ }^{3-8}$ with additional studies referring to 'extra-genital' infection without being more specific. ${ }^{9-12}$ Spontaneous clearance is often reported as a secondary endpoint with limited detail provided. 'Time to test-of-cure' and 'test and treat' studies account for the majority of data, usually reporting two testing events within a short time interval. ${ }^{4679}$ One study taking sequential cultures in patients with pharyngeal infection demonstrated 100\% clearance within 12 weeks. ${ }^{5}$ A more recent prospective study explored the role of gender, site of infection and bacterial load on the spontaneous clearance of NG and CT, but the sample size was small, with only 35 NG cases, limiting interpretation. ${ }^{13}$ Spontaneous clearance of CT has been more extensively reported with clearance rates varying, according to site from 9\% to 57\%. ${ }^{4}{ }^{9} 13-15$ Two studies found that a low bacterial load was positively associated with clearance $^{13} 14$ but there remain unanswered questions relating to why this happens in some, but not other cases.

In the current era of increasing concern regarding antimicrobial stewardship, further exploration is warranted including, specifically, how likely patients with NG are to clear their infection without antibiotic treatment. In this analysis of a subpopulation identified from a large multicentre UK cohort, ${ }^{16}$ we evaluate the occurrence of spontaneous clearance of NG at genital and extragenital sites, describe the associated time interval and explore demographic, clinical and behavioural factors associated with spontaneous clearance.

\section{METHODS}

\section{Gentamicin compared with Ceftriaxone for the Treatment of Gonorrhoea}

We analysed data collected in the Gentamicin compared with Ceftriaxone for the Treatment of Gonorrhoea (GToG) study, which has been previously reported. ${ }^{16}$ GToG was a randomised controlled trial which compared the efficacy of gentamicin and 


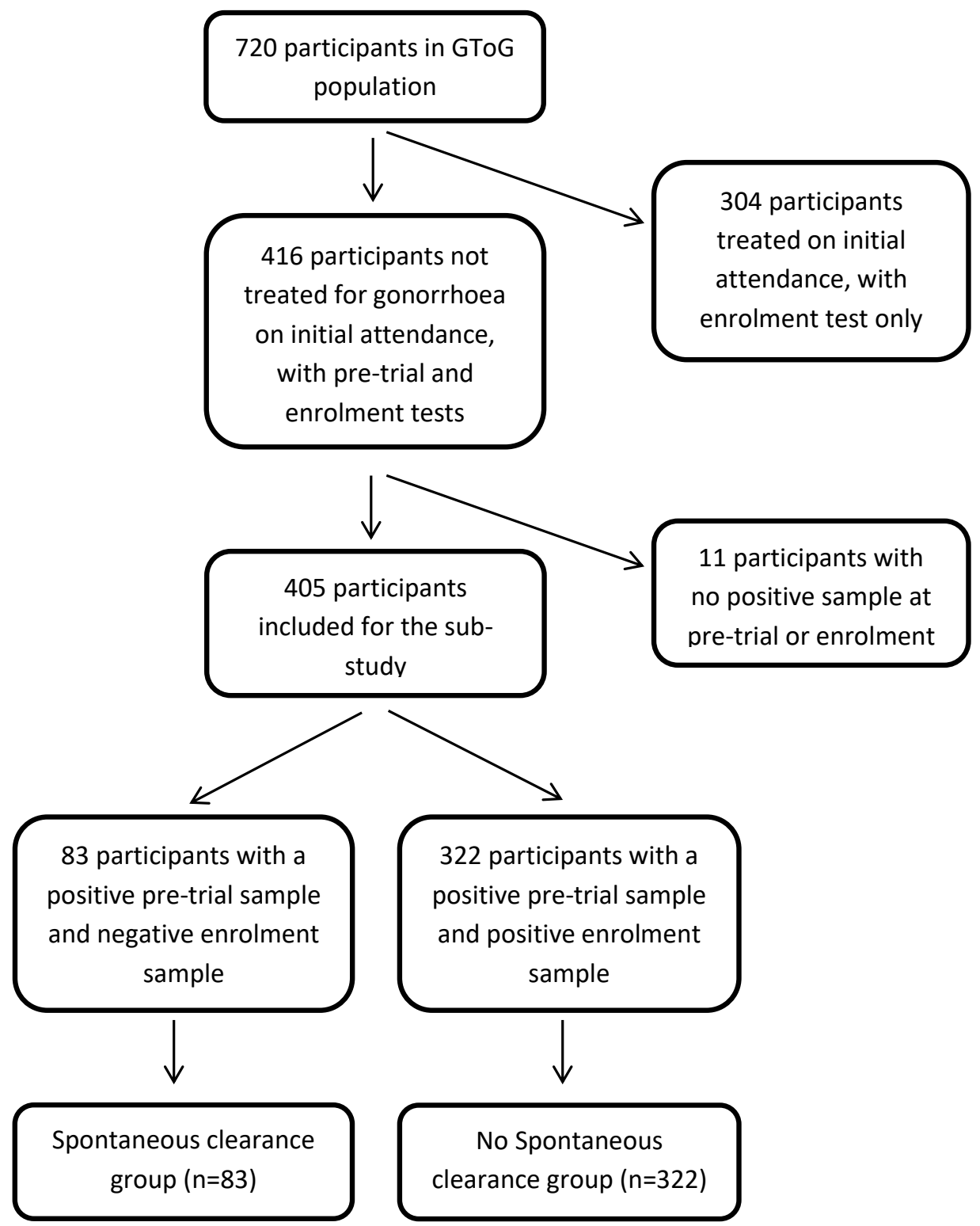

Figure 1 Identification of participants for inclusion into the substudy. GToG, Gentamicin compared with Ceftriaxone for the Treatment of Gonorrhoea.

ceftriaxone in patients with uncomplicated NG infection. Seven hundred and twenty patients with NG were enrolled on the basis of either (A) a positive NG nucleic acid amplification test (NAAT) (the 'pre-trial test') after which the participant was recalled for treatment (usually several days later) and enrolled into the trial, or (B) positive microscopy for NG at which time the participant was enrolled into the trial at the same attendance. At trial enrolment, a three-site testing (genital, rectum and pharynx) with NAAT and culture was performed for heterosexual women and men who have sex with men (MSM), and a single-site (genital) testing was undertaken for heterosexual males (the 'enrolment test'). Patients were excluded from participation in GToG if they had received ceftriaxone, azithromycin or gentamicin within the preceding 28 days.

\section{Substudy}

GToG participants who had both a pretrial and enrolment test were included in the substudy population (figure 1). Some participants' pretrial test results were positive but their enrolment tests were negative, indicating spontaneous clearance. Spontaneous clearance was assessed at the individual level and was defined as the participant having a positive pretrial NAAT and a negative enrolment NAAT at the same anatomical site (vagina and cervix were considered the same site) in the absence of antibiotic treatment. All participating laboratories performed confirmatory testing using the same sample in patients who had a positive NAAT result.

Those who spontaneously cleared according to the above definition were compared with those who did not to clear infection (both pretrial and enrolment tests were positive at that site); differences in demographics (age, gender), sexual history (sexual orientation, number of partners in the last 3 months, time from last sexual intercourse (LSI) to enrolment, history of NG infection, HIV status, concurrent CT diagnosis, symptoms 
and symptom type) and site of infection were explored. The GToG trial protocol did not require recording of the pretrial test date or test result unless the enrolment test was subsequently negative, so it was not possible in those who did not spontaneously clear infection to determine the time interval between the pretrial and enrolment tests. This was however assessed for those who spontaneously cleared infection, as both test dates were known.

\section{Statistical analysis}

IBM SPSS V.24 was used for analyses. Comparison between the two groups was made for each variable using t-test for continuous data or $\chi^{2}$ test (or Fisher's exact test when the expected value for a cell was <5) for categorical data. Mann-Whitney $\mathrm{U}$ test was used for non-normally distributed data. The time interval between last intercourse, pretrial tests (spontaneous clearance group only) and trial enrolment tests was recorded and the interval between last intercourse and enrolment tests was compared between the two groups.

\section{RESULTS}

The GToG study population included 720 participants. In this substudy 405 patients had a pretrial and enrolment test at the same anatomical site and were included in the analysis. There were 83 participants who fulfilled the definition of spontaneous clearance, therefore spontaneous clearance occurred in 83 of 405 participants $(20.5 \%)$ (figure 1$)$. Three hundred and four patients were tested and treated on the same day, of whom $94.7 \%$ were male (55.9\% MSM, 38.8\% heterosexual males), and were not included further in the main analysis. The characteristics of the GToG study population have been previously reported ${ }^{16}$ and those of the subpopulation used in this analysis are shown in table 1. Symptoms of genital discharge and dysuria, especially in male patients, would be associated with identification of NG on microscopy, enabling treatment on the day, so the high proportion with symptoms in this group was anticipated.

The time interval between LSI and enrolment tests was similar for the spontaneous clearance and no spontaneous clearance groups. Unsurprisingly this interval was shorter for those who were treated on the same day, who did not have any delay before being enrolled into the trial. The time interval between the pretrial and enrolment test was only calculated for the spontaneous clearance group (the pretrial test date was not recorded unless the enrolment test was negative). Sexual intercourse between pretrial and enrolment testing was reported by $32 / 83$ patients in the spontaneous clearance group (data not available for the no spontaneous clearance group).

Table 2 compares the demographics and sexual history of participants in the spontaneous clearance and no spontaneous clearance groups. The groups were similar in terms of age, gender, sexual orientation, HIV status and history of NG infection. The number of participants with concurrent CT infection was higher in the no spontaneous clearance group $(p=0.029)$. Overall, the presence of symptoms was no different between the two groups, however when separated out into subcategories of symptom type, dysuria occurred more frequently in the no spontaneous clearance group $(\mathrm{p}=0.035)$. This association persisted on multivariate analysis using the covariates of gender, sexual orientation (for males), dysuria and CT diagnosis (online supplementary web table 1). It was not possible to compare rates of positive culture for gonorrhoea between the two groups because cultures were not taken routinely from patients at their attendance for pretrial testing.

\begin{tabular}{|c|c|c|c|}
\hline & $\begin{array}{l}\text { Spontaneous } \\
\text { clearance group } \\
(n=83)\end{array}$ & $\begin{array}{l}\text { No spontaneous } \\
\text { clearance group } \\
(n=322)\end{array}$ & $\begin{array}{l}\text { Same-day } \\
\text { treatment group } \\
(\mathrm{n}=304)\end{array}$ \\
\hline \multicolumn{4}{|l|}{ Age (years) } \\
\hline Mean (SD) & $30.4(9.7)$ & $29.4(9.9)$ & $31.3(10.3)$ \\
\hline Max & 70.2 & 69.5 & 68.4 \\
\hline Min & 18.1 & 16.1 & 17.1 \\
\hline \multicolumn{4}{|c|}{ Gender and type of sexual contact, $n(\%)$} \\
\hline MSW & $10(12.0)$ & $24(7.5)$ & $118(38.8)$ \\
\hline MSM & $54(65.1)$ & $200(62.1)$ & $170(55.9)$ \\
\hline WSM & $19(22.9)$ & $97(30.1)$ & $15(4.93)$ \\
\hline TWSM & 0 & $1(0.3)$ & 0 \\
\hline No data & 0 & 0 & $1(0.3)$ \\
\hline \multicolumn{4}{|l|}{ Genital discharge } \\
\hline Female & $8 / 19(42.1 \%)$ & $39 / 97(40.2 \%)$ & $7 / 15(46.7 \%)$ \\
\hline Male & $1 / 64(1.6 \%)$ & $14 / 224(6.3 \%)$ & $260 / 288(90.3 \%)$ \\
\hline Transwoman & - & $0 / 1(0 \%)$ & - \\
\hline \multicolumn{4}{|l|}{ Dysuria } \\
\hline Female & $1 / 19(5.3 \%)$ & $26 / 97(26.8 \%)$ & $6 / 15(40.0 \%)$ \\
\hline Male & $3 / 64(4.7 \%)$ & $16 / 224(7.1 \%)$ & $226 / 288(78.4 \%)$ \\
\hline Transwoman & - & $0 / 1(0 \%)$ & - \\
\hline \multicolumn{4}{|l|}{ Rectal symptoms } \\
\hline Female & $2 / 19(10.5 \%)$ & $3 / 97(3.1 \%)$ & $2 / 15(13.3 \%)$ \\
\hline Male & $2 / 64(3.1 \%)$ & $18 / 224(8.0 \%)$ & $18 / 288(6.3 \%)$ \\
\hline Transwoman & - & $0 / 1(0 \%)$ & - \\
\hline \multicolumn{4}{|c|}{ Time interval (days) between pretrial and enrolment test } \\
\hline Median (IQR) & $10(7-15)$ & Missing data & Missing data \\
\hline Range & $2-55$ & & \\
\hline \multicolumn{4}{|c|}{ Time interval (days) between last sexual intercourse and enrolment test } \\
\hline Median (IQR) & $14(6-28)$ & $14(7-28)$ & $7(5-14)$ \\
\hline Range & $1-140$ & $0-210$ & $0-84$ \\
\hline
\end{tabular}

Rectal symptoms include rectal, discharge, pain, bleeding, tenesmus or constipation. MSM, man who has sex with men; MSW, man who has sex with women; TWSM, transwoman who has sex with men; WSM, woman who has sex with men.

Table 3 shows the site(s) of infection for individuals in the spontaneous clearance group and no spontaneous clearance group. In both men and women, clearance at genital, pharyngeal and rectal sites occurred. Of the 83 participants who cleared NG, two had multiple sites of infection on pretrial testing. One MSM had rectal and pharyngeal infections, the pharyngeal infection was cleared (rectal site not cleared) and one woman had genital, rectal and pharyngeal infections and cleared all sites. Pretrial sampling was undertaken at anatomical sites potentially exposed to infection as indicated by the sexual history (in accordance with local standard of care), rather than default three-site testing. It was not, therefore, possible to directly compare infection clearance ratios by specific sites but the number of infections at each site is shown in table 3 .

\section{DISCUSSION}

We report a spontaneous clearance rate for NG of $20.5 \%$ (83/405) over a median of 10 days (IQR 7-15), which is comparable to the $6 \%-33 \%$ rates reported in previously published studies. ${ }^{3} 8101213$ We found that clearance occurred at all anatomical sites (genital, pharyngeal and rectal) extending the previous literature which is focused on genital and pharyngeal infections. Determining an accurate measure of time from infection to clearance is difficult because the date of infection is generally not known. Date of symptom onset (where present) may be a useful 
Table 2 Comparison of demographics, clinical history and sexual behaviour between the spontaneous clearance and no spontaneous clearance groups

\begin{tabular}{|c|c|c|c|}
\hline & $\begin{array}{l}\text { Spontaneous } \\
\text { clearance group } \\
(\mathrm{n}=83)\end{array}$ & $\begin{array}{l}\text { No spontaneous } \\
\text { clearance group } \\
(n=322)\end{array}$ & $P$ value \\
\hline Age (years), mean (SD) & $30.4(9.72)$ & $29.4(9.90)$ & $0.380^{*}$ \\
\hline (Min;Max) & $(18.1 ; 70.2)$ & $(16.1 ; 69.5)$ & \\
\hline \multicolumn{4}{|l|}{ Gender, n (\%) } \\
\hline Female & $19(22.9)$ & $97(30.1)$ & \multirow[t]{2}{*}{0.188} \\
\hline Male & $64(77.1)$ & $224(69.8)$ & \\
\hline Trans & 0 & $1(0.3)$ & - \\
\hline \multicolumn{4}{|l|}{ Sexual orientation (men), $\mathrm{n}(\%)$} \\
\hline Heterosexual & $10(15.6)$ & $24(10.7)$ & \multirow[t]{2}{*}{0.283} \\
\hline MSM & $54(84.4)$ & $200(89.3)$ & \\
\hline $\begin{array}{l}\text { Number of partners in the last } \\
3 \text { months, median (IQR) }\end{array}$ & $3(1-4)$ & $2(1-5)$ & $0.966 \ddagger$ \\
\hline (Min;Max) & $(0 ; 100)$ & $(0 ; 120)$ & \\
\hline \multicolumn{4}{|c|}{ Number of previous NG episodes, $\mathrm{n}(\%)$} \\
\hline None/unknown & $46(55.4)$ & $188(58.4)$ & \multirow[t]{3}{*}{0.434} \\
\hline One & $26(31.3)$ & $80(24.8)$ & \\
\hline Two or more & $11(13.3)$ & $54(16.8)$ & \\
\hline \multicolumn{4}{|l|}{ HIV status, $\mathrm{n}(\%)$} \\
\hline Negative & $62(74.7)$ & $210(65.2)$ & \multirow[t]{3}{*}{0.213} \\
\hline Positive & $8(9.6)$ & $52(16.1)$ & \\
\hline Unknown & $13(15.7)$ & $60(18.6)$ & \\
\hline \multicolumn{4}{|l|}{ Concurrent CT, n (\%) } \\
\hline Negative & $72(88.9)$ & $245(78.0)$ & \multirow[t]{2}{*}{0.029} \\
\hline Positive & $9(11.1)$ & $69(22.0)$ & \\
\hline $\begin{array}{l}\text { Interval between last sexual } \\
\text { contact and enrolment test } \\
\text { (days), median (IQR) }\end{array}$ & $14(6-28)$ & $14(7-28)$ & $0.978 \ddagger$ \\
\hline (Min;Max) & $(1 ; 140)$ & $(0 ; 210)$ & \\
\hline \multicolumn{4}{|l|}{ Genital discharge, $\mathrm{n}(\%)$} \\
\hline No & $74(89.2)$ & $269(83.5)$ & \multirow[t]{2}{*}{0.205} \\
\hline Yes & $9(10.8)$ & $53(16.5)$ & \\
\hline \multicolumn{4}{|l|}{ Dysuria, n (\%) } \\
\hline No & $79(95.2)$ & $280(87.0)$ & \multirow[t]{2}{*}{0.035} \\
\hline Yes & $4(4.8)$ & $42(13.0)$ & \\
\hline \multicolumn{4}{|c|}{ Bleeding symptoms (intermenstrual or postcoital bleeding), n (\%) } \\
\hline No & $17(89.5)$ & 79 (81.4) & \multirow[t]{2}{*}{$0.521 \dagger$} \\
\hline Yes & $2(10.5)$ & $18(18.6)$ & \\
\hline \multicolumn{4}{|c|}{ Rectal symptoms (rectal discharge, pain, bleeding, tenesmus or constipation), $\mathrm{n}(\%)$} \\
\hline No & $79(95.2)$ & $301(93.5)$ & \multirow[t]{2}{*}{0.566} \\
\hline Yes & $4(4.8)$ & $21(6.5)$ & \\
\hline \multicolumn{4}{|c|}{ Pharyngeal symptom—sore throat, $\mathrm{n}(\%)$} \\
\hline No & $66(79.5)$ & $268(83.2)$ & \multirow[t]{2}{*}{0.428} \\
\hline Yes & $17(20.5)$ & $54(16.8)$ & \\
\hline \multicolumn{4}{|c|}{ NAAT platform used for pretrial testing, $\mathrm{n}(\%)$} \\
\hline $\begin{array}{l}\text { Hologic Aptima combo } 2 \\
\text { Assay }\end{array}$ & $60(72.3)$ & $248(77.0)$ & \multirow[t]{3}{*}{0.270} \\
\hline $\begin{array}{l}\text { Becton Dickinson ProbeTec } \\
\text { ET CT/NG Amplified DNA } \\
\text { Assay }\end{array}$ & $21(25.3)$ & $59(18.3)$ & \\
\hline Other & $2(2.4)$ & $15(4.7)$ & \\
\hline
\end{tabular}

*Independent sample t-test.

†Fisher's exact test for data with group size $<5$.

$\ddagger$ Mann-Whitney $\mathrm{U}$ test for non-normally distributed data.

CT, Chlamydia trachomatis; MSM, man who has sex with men; NAAT, Nucleic acid amplification test; NG, Neisseria gonorrhoeae.

surrogate marker for date of infection but many individuals with symptoms receive immediate empirical treatment which limits its utility to measure duration of infection.
Comparing the group of participants who cleared NG infection and those who did not, there were no differences in patient demographics, clinical presentation or sexual history. In particular, a history of previous NG was not associated with spontaneous clearance suggesting that acquired immunity to $\mathrm{N}$. gonorrhoeae was not a major factor. ${ }^{17}$ Individuals who cleared NG before antibiotic treatment were less likely to give a history of dysuria or have concurrent CT. Even after the exclusion of those who were the most symptomatic in this population (those who were treated on the same day), there was a significant difference between the spontaneous clearance group and the no spontaneous clearance group in the proportion of those who had dysuria. The absence of dysuria might indicate a lower bacterial load although as this has not been extensively investigated in NG infection the significance remains uncertain. ${ }^{13} 18$ Coinfection with CT is common in NG- infected individuals ${ }^{19-21}$ but it is not clear why it was less frequent in the spontaneous clearance group. Poor test specificity is unlikely to account for all the observed cases of spontaneous clearance since the positive predictive value of the NG NAAT, with confirmatory testing, is high. $^{22} 23$

As a subanalysis of the GToG trial, the study was not designed to investigate the spontaneous clearance rate of NG infection. We excluded those who were diagnosed based on their initial microscopy findings, who were usually symptomatic, and therefore our results should not be extrapolated to this group. The pretrial sampling (used to establish eligibility for the trial) was not a trial procedure and was performed according to local guidelines. As such, not all potentially infected sites were sampled in all patients, and this may have introduced a bias towards detecting clearance at the genital site since this would be most frequently sampled site. It also meant that we could not make meaningful comparisons between the rates of clearance between different anatomical sites. In common with most other studies evaluating spontaneous clearance of NG, we only had two testing time points because it was not possible to withhold treatment after making a diagnosis. This, combined with uncertainty on when an infection was acquired, makes it difficult to assess how quickly clearance of infection occurs and whether it occurs in a linear (continuous rate of clearance over time) or non-linear (eg, clearance more likely shortly after infection is acquired) way. We also acknowledge that by performing a large number of statistical comparisons, multiplicity increases the risk of false associations being identified. A final limitation is that a longer period of follow-up in those who had a negative repeat test is desirable to ensure that this represents 'cure' and not just a transient suppression of the bacterial load.

The strengths of the study were that the cohort was drawn from participants in a well-conducted, large, multicentre UK study, which is broadly representative of the population infected with NG in England and Wales. ${ }^{24}$ It included heterosexual men, women and MSM, and we report a large number of infections including genital and extragenital sites. Data were collected within a large randomised controlled trial and the data quality was likely to be high.

Our findings suggest that it may be possible to reduce antimicrobial prescribing by retesting individuals to confirm the presence of infection prior to giving treatment. This could be done with conventional NAAT testing, provided results are available promptly and the patient is counselled appropriately, especially for infections where local spread of infection over a short time period is unlikely, such as pharyngeal and rectal NG. Alternatively, point-of-care testing could provide rapid confirmation of infection, prior to treatment being given, and the practicalities 
Table 3 Site(s) of infection in the spontaneous clearance and no spontaneous clearance groups

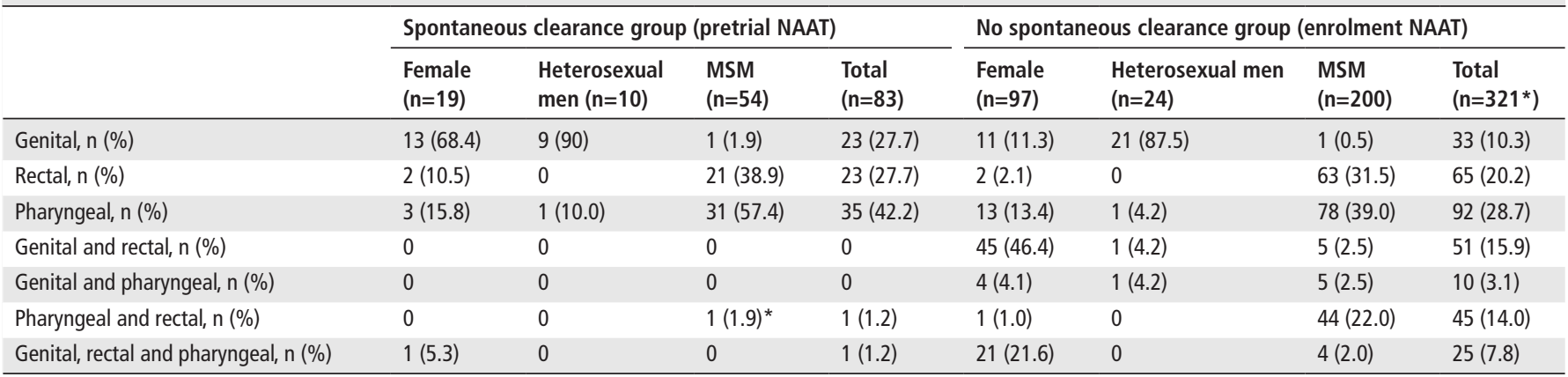

One transperson not included due to small numbers.

*This patient cleared infection at the pharyngeal site but not the rectal site.

MSM, man who has sex with men; NAAT, Nucleic acid amplification test.

and cost-effectiveness of this approach need further exploration. ${ }^{25}$ We have shown that the time interval between testing and clearance can be small, occurring after a median of 10 days for this cohort, and others have also demonstrated that the duration of infection can be short especially in the pharynx. ${ }^{26}$ UK national guidance is to test 'higher risk' clinic attendees on a three monthly basis $^{27}$ but our findings suggest that this may miss infections, as the time to clearance is often shorter than this interval. This has implications for disease control via partner notification and health education because patients can become infected and clear infection within this screening interval. An awareness of possible spontaneous clearance of gonorrhoea without treatment is also relevant in medicolegal cases as a possible explanation for the absence of infection when testing an alleged perpetrator or assault survivor.

\section{CONCLUSION}

In our cohort, $20.5 \%$ of those recalled for treatment of NG infection cleared their infection within a median of 10 days before receiving antimicrobial therapy. Concurrent CT infection and the presence of dysuria were negatively associated with spontaneous clearance of NG. The use of point-of-care tests in confirming positive test results prior to treatment has the potential to reduce antibiotic use in this high-risk group of patients. We suggest that further work is required to investigate spontaneous clearance, including the assessment of bacterial load and whether clearance persists over a longer time period.

\section{Key messages}

- Spontaneous clearance of gonorrhoea without antibiotic treatment occurred in $20.5 \%$ (83/405) of patients over a median of 10 days.

- Clinicians should be aware that spontaneous clearance of Neisseria gonorrhoeae can occur, and this may avoid unnecessary treatment in some patients.

- Spontaneous clearance was less likely in those reporting dysuria, which may indicate that it occurs more commonly when the bacterial load is low.

Handling editor Henry John Christiaan de Vries

Acknowledgements The authors thank Wei Tan and Trish Hepburn for collation of the sub-data set, Peter Nightingale for support with the statistical analysis and Michelle Cole for review of the manuscript.
Contributors JR and SM conceived and designed the study. OCA and SM carried out the statistical analyses. SM and JR drafted the manuscript. All authors approved the final manuscript.

Funding The GToG study was funded by the National Institute for Health Research (NIHR) Health Technology Assessment and registered prior to start of recruitment (ISRCTN51783227).

Disclaimer The views expressed are those of the author(s) and not necessarily those of the NIHR or the Department of Health and Social Care.

Competing interests JR reports personal fees from GSK Pharma, Mycovia and Nabriva Therapeutics as well as ownership of shares in GSK Pharma and AstraZeneca Pharma; is the author of the UK and European Guidelines on Pelvic Inflammatory Disease; is a member of the European Sexually Transmitted Infections Guidelines Editorial Board; and is a member of the National Institute for Health Research Funding Committee (Health Technology Assessment programme). He is an NIHR Journals editor and associate editor of Sexually Transmitted Infections journal. He is an officer of the International Union against Sexually Transmitted Infections (treasurer), and a charity trustee of the Sexually Transmitted Infections Research Foundation.

\section{Patient consent for publication Not required.}

Ethics approval Research ethics approval was granted for the 'Gentamicin for the Treatment of Gonorrhoea' trial from the Health Research Authority South CentralOxford C Research Ethics Committee (14/SC/1030).

Provenance and peer review Not commissioned; externally peer reviewed

Data availability statement All data relevant to the study are included in the article or uploaded as supplementary information.

\section{ORCID iDs}

Sarah Mensforth http://orcid.org/0000-0002-0737-0157

Oluseyi Cyril Ayinde http://orcid.org/0000-0003-2097-8949

\section{REFERENCES}

1 Fifer H, Saunders J, Soni S, et al. British Association for Sexual Health and HIV national guideline for the management of infection with Neisseria gonorrhoeae (2019), 2019. Available: https://www.bashhguidelines.org/media/1208/gc-2019.pdf [Accessed 28 Jan 2019].

2 Mensforth S, Ross JDC. Assessing the Frequency of Spontaneous Clearance of Gonococcal Infection in the Absence of Antibiotic Therapy: a review of the literature The International Union Against Sexually Transmitted Infections Asia Pacific Conference 2018, New Zealand [November 2018]. Conference Poster presentation., 2018. Available: https://az659834.vo.msecnd.net/eventsairaueprod/production-ashmpublic/985872a73ea64df196772b80254c093f

3 Chow EPF, Lee D, Tabrizi SN, et al. Detection of Neisseria gonorrhoeae in the pharynx and saliva: implications for gonorrhoea transmission. Sex Transm Infect 2016:92:347-9.

4 Apewokin SK, Geisler WM, Bachmann LH. Spontaneous resolution of extragenital chlamydial and gonococcal infections prior to therapy. Sex Transm Dis 2010;37:1-44.

5 Wallin J, Siegel MS. Pharyngeal Neisseria gonorrhoeae: coloniser or pathogen? $\mathrm{Br}$ Med J 1979;1:1462-3.

6 Hutt DM, Judson FN. Epidemiology and treatment of oropharyngeal gonorrhea. Ann Intern Med 1986;104:655-8. 
7 Bissessor M, Whiley D, Bradshaw CS, et al. P2.033 Isolation of Neisseria Gonorrhoeae from the Tonsils and Posterior Oropharynx Using Culture. Sex Transm Infect 2013;89:A97.4-8.

8 Hananta IPY, De Vries HJC, van Dam AP, et al. Persistence after treatment of pharyngeal gonococcal infections in patients of the STI clinic, Amsterdam, the Netherlands, 2012-2015: a retrospective cohort study. Sex Transm Infect 2017:93:467-71.

9 Van Liere G, Dukers-Muijrers N, Hoebe C, et al. Substantial natural clearance of genital and extragenital Chlamydia trachomatis and Neisseria gonorrhoeae in STD clinic attendees. Sexually Transmitted Infections 2013;89:A206.

10 Wind CM, Schim van der Loeff MF, Unemo M, et al. Test of cure for anogenital gonorrhoea using modern RNA-based and DNA-based nucleic acid amplification tests: a prospective cohort study. Clin Infect Dis 2016;62:1348-55.

11 Sultan B, Oakland C, Brima N, et al. Feasibility study to determine the time taken for NAATs tests to become negative following treatment for Chlamydia trachomatis and Neisseria gonorrhoeae in men and women. Sexually Transmitted Infections 2016;92:0023.

12 Nguyen TQ, Cohen SE, Noohi T, et al. P09.15 Time to clearance for molecular testof-cure among men treated for urethral, pharyngeal, or rectal gonorrhoea in san francisco,2013-2014. Sex Transm Infect 2015;91:A153

13 van Liere GAFS, Hoebe CJPA, Dirks JA, et al. Spontaneous clearance of urogenital, anorectal and oropharyngeal Chlamydia trachomatis and Neisseria gonorrhoeae in women, MSM and heterosexual men visiting the STI clinic: a prospective cohort study. Sex Transm Infect 2019;95:505-10.

14 van Rooijen MS, van der Loeff MFS, Morré SA, et al. Spontaneous pharyngeal Chlamydia trachomatis RNA clearance. A cross-sectional study followed by a cohort study of untreated STI clinic patients in Amsterdam, the Netherlands. Sex Transm Infect 2015;91:157-64.

15 Geisler WM, Wang C, Morrison SG, et al. The natural history of untreated Chlamydia trachomatis infection in the interval between screening and returning for treatment. Sex Transm Dis 2008;35:119-23.

16 Ross JDC, Brittain C, Cole M, et al. Gentamicin compared with ceftriaxone for the treatment of gonorrhoea (G-ToG): a randomised non-inferiority trial. Lancet 2019;393:2511-20.
17 Hedges SR, Mayo MS, Mestecky J, et al. Limited local and systemic antibody responses to Neisseria gonorrhoeae during uncomplicated genital infections. Infect Immun 1999;67:3937-46.

18 Stupiansky NW, Van Der Pol B, Williams JA, et al. The natural history of incident gonococcal infection in adolescent women. Sex Transm Dis 2011;38:1-54.

19 Creighton S, Tenant-Flowers M, Taylor CB, et al. Co-Infection with gonorrhoea and Chlamydia: how much is there and what does it mean? Int J STD AIDS 2003;14:109-13.

20 McMillan A, Manavi K, Young H. Concurrent gonococcal and chlamydial infections among men attending a sexually transmitted diseases clinic. Int J STD AIDS 2005; 16:357-61.

21 Forward KR. Risk of coinfection with Chlamydia trachomatis and Neisseria gonorrhoeae in nova Scotia. Can I Infect Dis Med Microbiol 2010;21:e84-6.

22 Katz AR, Effler PV, Ohye RG, et al. False-Positive gonorrhea test results with a nucleic acid amplification test: the impact of low prevalence on positive predictive value. Clin Infect Dis 2004;38:814-9.

23 Hook III EW, Ndowa F, Mabey D, et al. Choosing tests for sexually transmitted infections. In: Unemo M, ed. Laboratory diagnosis of sexually transmitted infections, including human immunodeficiency virus. Geneva: World Health Organisation, 2013: 1-8.

24 Ivanov Z, Allen H, Sadouki Z, et al. Surveillance of antimicrobial resistance in Neisseria gonorrhoeae in England and Wales. key findings from the gonococcal resistance to antimicrobials surveillance programme (GRASP) London public health England, 2018. Available: https://assets.publishing.service.gov.uk/government/uploads/system/ uploads/attachment_data/file/746261/GRASP_2017_report.pdf[Accessed 28 Oct 2019].

25 Turner KME, Round J, Horner P, et al. An early evaluation of clinical and economic costs and benefits of implementing point of care NAAT tests for Chlamydia trachomatis and Neisseria gonorrhoea in genitourinary medicine clinics in England. Sex Transm Infect 2014;90:104-11.

26 Barbee L, Soge O, Haglund M, et al. 002.4 Incidence and duration of pharyngeal and rectal gonorrhea and chlamydia among high-risk men who have sex with men (MSM). Sexually Transmitted Infections 2019;95:A40.

27 Clutterbuck D, Asboe D, Barber T, et al. United Kingdom national guideline on the sexual health care of men who have sex with men. Int J STD AIDS 2016;2018:956462417746897. 